\title{
Building a Comprehensive Spatio-Temporal Database of Floodplain Inundation for Environmental Management in the Murray-Darling Basin, Australia
}

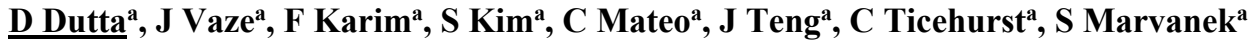 \\ ${ }^{a}$ CSIRO Land and Water, Canberra, ACT, Australia \\ Email: Dushmanta.dutta@,csiro.au
}

\begin{abstract}
This paper describes an innovative large-scale floodplain modelling approach that was developed by integrating a suite of models (landscape model, hydrodynamic model and water balance model) and GIS for producing inundation maps at very high temporal and spatial resolutions under different antecedent conditions. A two-dimensional hydrodynamic model was initially calibrated and validated for historical events using observed water levels and flood maps derived from Landsat imagery. The results demonstrate highly satisfactory performance of the model in simulating floods of different magnitudes in a number of floodplains. The hydrodynamic model outputs were then processed using a simplified hydraulic and hydrological water balance model to simulate a range of flood events to produce a comprehensive and very high spatial resolution floodplain inundation database under different flow ranges and antecedent conditions. The model outputs are used by the Murray Darling Basin Authority (MDBA), Australia for decision making process for environmental management. The paper presents the overview of the methodology, the results of calibration and validation of the model and describe the inundation database created for the Lower Balonne floodplain in the Murray Darling Basin.
\end{abstract}

Keywords: Hydrodynamic modelling, floodplain inundation, environmental management, Murray-Darling Basin, simplified hydraulic model 


\section{INTRODUCTION}

Environmental flow management is a critical aspect of river basin managements, in particular, in dry continent like Australia. Environmental flow was one of the key focuses in the development and implementation of the basin plan in the Murray-Darling Basin (MDB), which is one of the largest river basins in Australia with an area of about 1 million $\mathrm{km}^{2}$. The basin has over 30,000 wetlands and many of those are of national and international significance (EA, 2001). The basin plan has aimed to return MDB to a healthy, working condition so as to have a sustainable and productive economic future (MDBA, 2012a). One of the main objectives of the basin plan is to ensure that the key environmental assets (including wetlands and floodplains) are protected and progressively improved, and there is adequate water to sustain their ecological resilience during periods of drought. Floodplain wetlands rely on inflow from catchments to maintain the flooding and drying cycles critical to their ecological integrity (Powell et al., 2008). The environmental benefits of water flowing into wetlands and over floodplains depend on the extent, depth, duration and frequency of the inundation. Floodplain inundation in wetlands are influenced not only by upstream inflows but also by local climatic and antecedent conditions. Development of a detailed understanding of wetland hydrology and inundation characteristics under different climatic and antecedent conditions is imperative for effective environmental management (Dutta et al., 2013).

Traditionally, two-dimensional hydrodynamic (HD) models are used for flood inundation modelling (Dutta et al., 2009). However, such models are computationally intensive and hence, it becomes difficult to simulate floodplain inundation at a very high spatial resolutions for large floodplains for multiple events under different climatic conditions using HD model alone. Also, most of the available HD models at present can't adequately consider losses from floodplains under different antecedent conditions. We have developed an innovative large-scale floodplain modelling approach by integrating a suite of models (landscape model, hydrodynamic model and simplified hydraulic and water balance model) and GIS for producing inundation maps at very high temporal and spatial resolutions under different local climatic and antecedent conditions. A two-dimensional hydrodynamic model was initially calibrated and validated for historical events using observed water levels and flood maps derived from Landsat imagery. The hydrodynamic model outputs were then processed using a simplified hydraulic and hydrological water balance model (Teng et al., 2015) to simulate a range of flood events to produce a comprehensive and very high spatial resolution floodplain inundation database under different flow ranges and antecedent conditions. The model was implemented in a number of floodplains in the MDB. The paper presents the overview of the methodology, the results of calibration and validation of the model and describe the inundation database created for the Lower Balonne in the MDB.

\section{METHODOLOGY}

The modelling methodology has four components: 1) Landscape model, 2) two-dimensional hydrodynamic (2D HD) model; 3) simplified hydraulic model; and 4) water balance model. The Landscape model, which is used to produce local runoff for the modelling domain, is the Australian Water Resources Assessment Landscape Model (AWRA-L). AWRA-L is a grid-based biophysical model of the water balance between the atmosphere, the soil, unsaturated zones and confined and unconfined groundwater stores. The model runs on a uniform 0.05 degree x 0.05 degree resolution grid network (approximately $5 \mathrm{~km} \mathrm{x} 5 \mathrm{~km}$ ) covering the entire Australian continent at a daily time step. The details of AWRA-L are presented in Viney et al. (2014). The model was regionally calibrated using a number of headwater catchments in the vicinity of the study area for this application. The simulated gridded local runoff for different flood events were resampled to subcatchment levels for hydrodynamic modelling.

The MIKE21 2D HD model was used for floodplain inundation at a lower spatial resolution (90-m) that was suitable for modelling a large number of flood events within reasonable computational time. MIKE 21 is the computational hydrodynamic module of MIKEFLOOD software package. It simulates the water level variation and flow in response to a variety of forcing functions in floodplains, lakes, estuaries, bays and coastal areas. In this study, the entire study area was divided into a number of subcatchments and local runoff generated from AWRA-L for each subcatchment was incorporated as source at the outlet of the subcatchment. The observed or simulated flow and water level data the gauges at upstream and downstream ends were used as the boundary conditions. The bed resistance was defined using Manning's roughness coefficient, which was initially derived based on the landcover map. The simplified hydraulic model was designed to resample the simulated lower resolution flood inundation outputs by the MIKE21 HD model to finder spatial resolution (5-m) based on very high resolution topographic data, slope and flow directions. The finer resolution outputs were used to calibrate the HD model parameters by adjusting the Manning roughness coefficient. Observed water levels at a number of gauges within the study domain and food maps derived from Landsat TM imagery for a number of selected historical flood events were used for the model calibration. 
The water balance model was used to undertake water balance modelling using finer resolution flood maps taking into consideration of net evaporation and infiltration for different antecedent soil moisture conditions for the selected flood event. In the water balance modelling, the infiltration rate is calculated using the modified cumulative Horton's equation (Horton, 1933; Vaze and Chiew, 2003). The consideration for antecedent soil moisture condition at the start of any modelled flood event is accounted for by adjusting the soil moisture storage to different levels of soil saturation.

\section{STUDY AREA}

The Lower Balonne floodplain is located in the Condamine-Balonne region of the Murray Darling Basin, which is one of the largest river basins in Australia with an area of about 1 million $\mathrm{km}^{2}$ with over 30,000 floodplains and wetlands (Figure 1). The Lower Balonne floodplain is located in the downstream of the Balonne River System and is one of the most complex floodplains with the flood hydraulics of the system resembling that of a delta with multiple channels. After St George, the Balonne River divides into five separate channels. The Culgoa and Narran Rivers are the main channels, conveying $35 \%$ and $28 \%$ of the long-term mean annual flow at St George respectively; while the Ballandool and Bokhara Rivers and Birrie Creek flow only during higher discharge periods (Thoms et al., 2002; MDBA, 2012b) (Figure 2.3). Approximately $30 \%$ of the system is in Queensland and 70\% in New South Wales (McCosker, 1996) and there are a number of significant wetlands located in the system. The area is frequently flooded with flows of up to $30,000 \mathrm{ML} / \mathrm{d}$ dispersing into many small flood channels. A typical inundation map of the area is shown in Figure 2.4. At higher flows, water spreads out

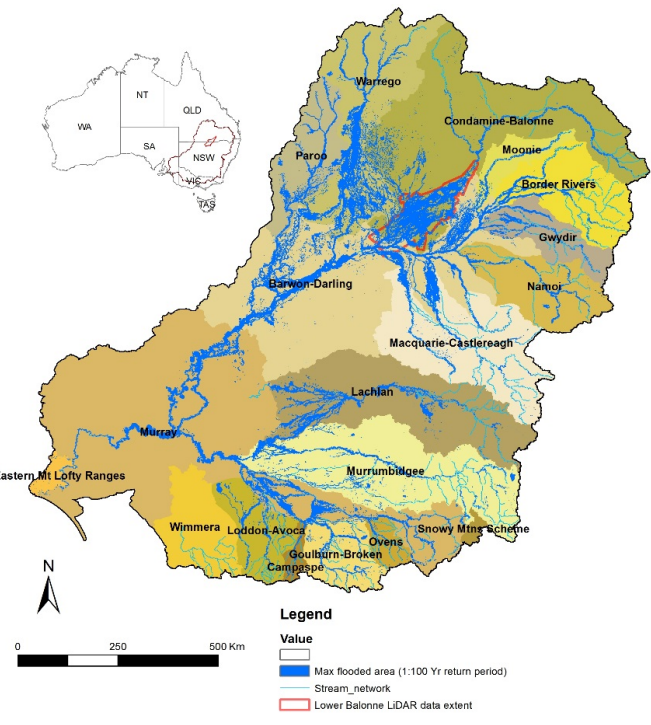

Figure 1. Map showing the extent of LiDAR data for Lower Balonne floodplain in the MDB. over the floodplain and a significant portion does not return to the river as a result of evaporation and infiltration (MDBA, 2012b). As such, it is important to incorporate these processes (open water evaporation and infiltration from floodplain) in inundation modelling for accurate estimates of inundated areas.

One of the key requirements of floodplain inundation modelling was to utilise LiDAR data for producing inundation maps at very high spatial resolutions. The modelling boundary for LBS was therefore determined based on the extent of available LiDAR data that was collected recently by Geoscience Australia, as shown in Figure 1. The red color polygon shows the extent of the collected LiDAR data for the floodplain, which covers an area of $18,412 \mathrm{~km}^{2}$. Locations of streamflow gauges within the modelling domain is shown in Figure 2a.

\section{HD MODEL SETUP FOR CALIBRATION AND VALIDATION}

Runoff data simulated by the gridded AWRA-L model version 5.0 at $0.05^{\circ}(\sim 5 \mathrm{~km})$ resolution grids was used to generate catchment runoff for hydrodynamic modelling. The daily time series of AWRA-L model outputs were available for the period of 1911-2015. The hydrodynamic modelling domain (covering the LiDAR data extent) for the Lower-Balonne floodplain was divided into a large number of subcatchments as shown in Figure $2 \mathrm{~b}$ using flow accumulation and flow direction maps derived from the LiDAR data to distribute the gridded runoff within the modelling domain. AWRA-l gridded runoff was used to compute average runoff for the subcatchments and ungauged inflow at model boundaries where observed data were not unavailable.

The 5-m resolution LiDAR data were resampled to 90-m resolution for MIKE21 HD modelling due to the computational time. The stream network generated from 1-m LiDAR data was used to accurately define the flow paths along the stream network in 90-m DEM and for identifying the correct locations of the gauging stations to define the boundary conditions and to record simulated data for the calibration and validation of the model. Cross-sections data available at the gauging stations were used to obtain the actual datum of gauged water levels that are used for model validation. Gauged water level and streamflow data were used both as boundary conditions in the hydrodynamic model as well as for the calibration and validation of the model. Surface roughness is a calibration parameter in hydrodynamic modelling. The initial roughness values for the modelling domain were assigned based on the land cover map. Four flood events of different magnitudes were selected for the model calibration and validations as shown in Table 1. 


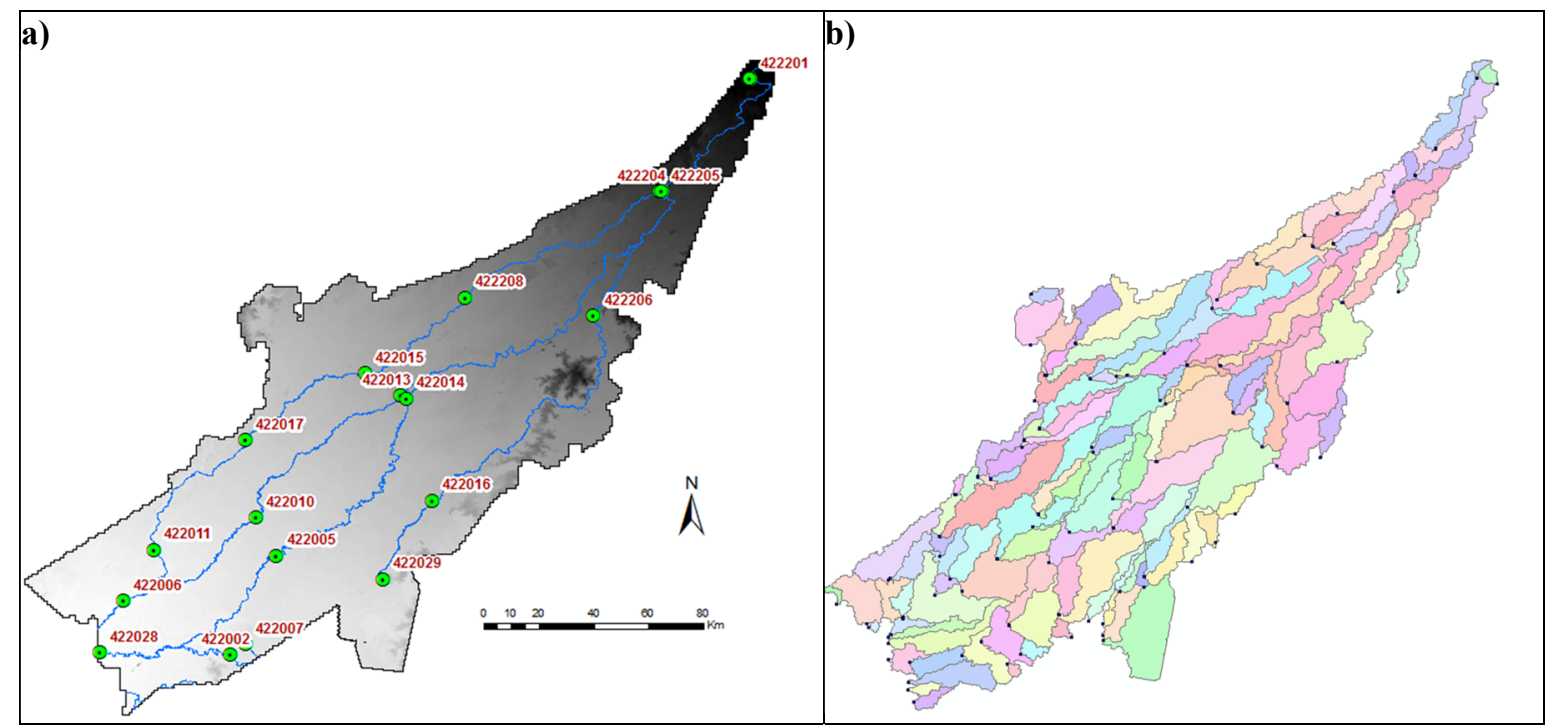

Figure 2. a) Locations of the streamflow gauges and b) sub-catchments and pour points generated for the Lower Balonne floodplain for hydrodynamic modelling.

Table 1. Selected flood events for model calibration and validation.

\begin{tabular}{llc}
\hline Year of selected flood event & Period of inundation modelling & Used for \\
\hline $\mathbf{1 9 9 5 - 1 9 9 6}$ & $27 / 12 / 1995-30 / 01 / 1996$ & Validation \\
$\mathbf{2 0 0 8}$ & $19 / 01 / 2008-23 / 02 / 2008$ & Validation \\
$\mathbf{2 0 1 0 - 2 0 1 1}$ & $30 / 12 / 2010-31 / 01 / 2011$ & Calibration \\
$\mathbf{2 0 1 2}$ & $28 / 01 / 2012-02 / 03 / 2012$ & Validation \\
\hline
\end{tabular}

\section{RESULTS}

The main datasets used for the model calibration and validation were the daily observed water levels at different gauging stations and flood maps derived from Landsat imagery. Figure 3 presents the comparison of the simulated daily water levels against the observed daily water levels at a number of key gauges during the periods of the four selected flood events. As can be seen from the figures for different gauges, the model performed reasonably well in water level simulations in both calibration and validation events. In particular, the model performance was highly satisfactory during the period of the high flood events of 2010-11 and 2012. Table 2 presents the linear correlation coefficients between the observed and simulated daily water levels for different gauges for the selected events. The variations in median correlations are above 0.6 for all the simulated flood events.

The simulated inundation maps for different flood events were compared against the flood maps derived from the Landsat imagery for different dates during the period of simulation. Only a few good quality Landsat images (with low could cover) were available during the selected flood events. The study area was covered by multiple Landsat scenes and the dates of image captures varied from scene to scene due to different flight paths with a gap of at least 8 days in most of the cases. Because of that, the comparison between the simulated flood extents and Landsat flood maps was undertaken for the modelled areas covered by different scenes. Figure 4 presents the comparison for two dates $((21 / 01 / 2011$ and 17/02/2012) covering two simulated flood events. Landsat flood map was available only for part of the modelled area for 17/02/2012. The agreement between

Table 2. Linear correlation coefficients between observed and simulated daily water levels at different gauges.

\begin{tabular}{lllll} 
Gauge ID & $1995-96$ & 2008 & $2010-11$ & 2012 \\
\hline 422005 & 0.15 & 0.75 & 0.78 & 0.44 \\
422006 & 0.25 & 0.95 & 0.63 & 0.11 \\
422010 & 0.63 & 0.38 & 0.65 & 0.34 \\
422011 & 0.26 & 0.87 & 0.58 & 0.24 \\
422013 & 0.81 & 0.80 & 0.63 & \\
422014 & 0.86 & & 1.00 & \\
422015 & 0.61 & 0.97 & 1.00 & 0.27 \\
422016 & 0.13 & 0.83 & 0.55 & 0.71 \\
422017 & 0.33 & 0.97 & 0.76 & 0.28 \\
422029 & & 0.94 & 0.78 & 0.25 \\
422204 & 1.00 & 0.11 & 1.00 & 0.93 \\
422205 & 1.00 & 0.11 & 1.00 & 0.93 \\
422208 & & 0.69 & & 0.49 \\
\hline
\end{tabular}


Dutta et al., Building a Comprehensive Spatio-Temporal Database of Floodplain Inundation ......

the simulated and Landsat flood maps were highly satisfactory for most of the areas. The cell-to-cell comparison between two datasets show that the agreement varies between $50-70 \%$ for different scenes and dates, which is satisfactory. The flooding characteristics in Lower Balonne floodplain are very complex with four different river systems (Balonne, Culgoa, Birrie/Bokhara and Narran) contribute to flooding through overbank flow. For similar rainfall pattern, the flood extents can significantly vary depending on the inflows to these river systems and soil moisture conditions. Based on the comparisons between the simulated and observed water levels at different observed gauges, the model has captured the complex flood characteristics reasonably well.

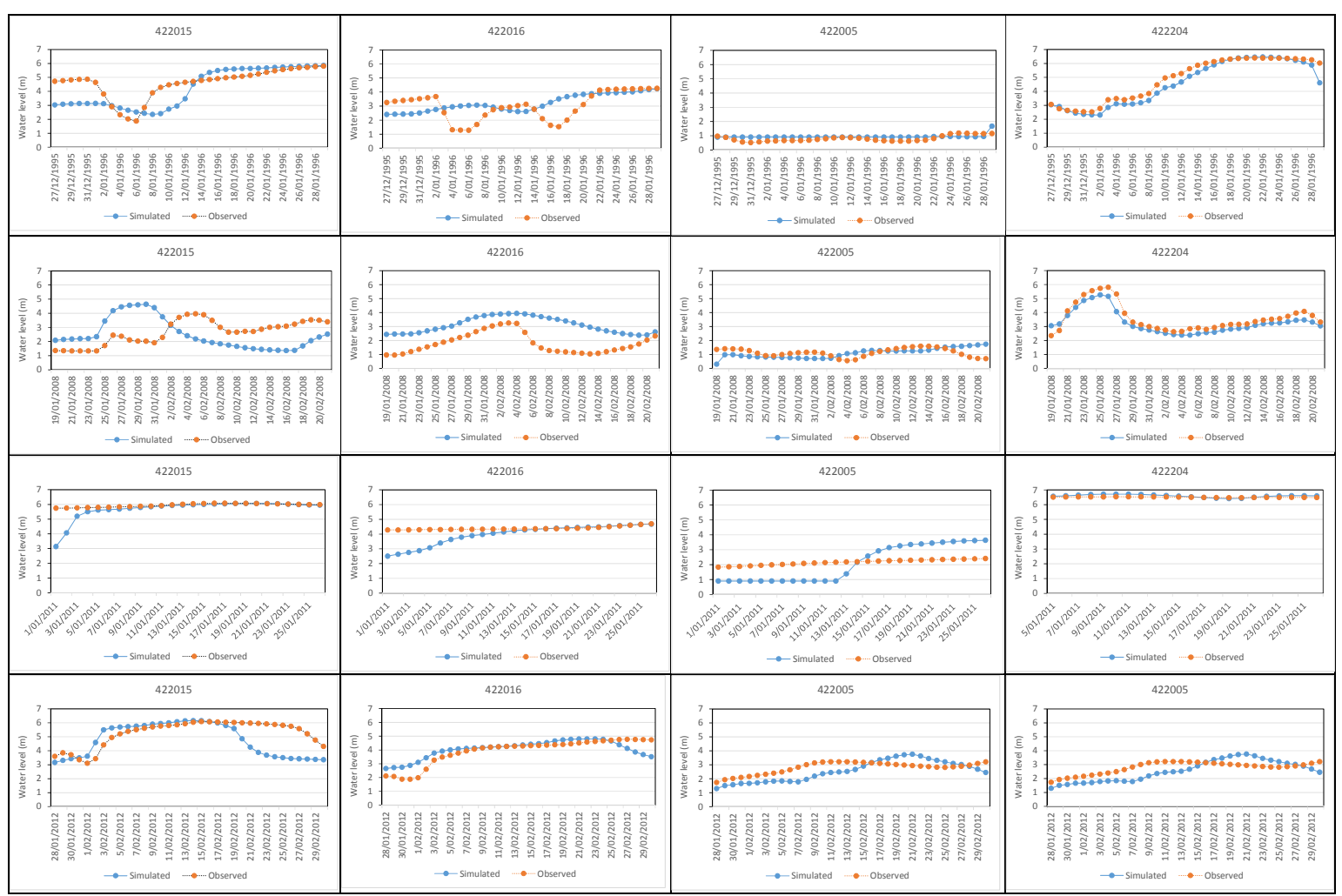

Figure 3. Comparison of simulated and observed daily water levels at a number of selected gauges during the periods of the selected historical flood events

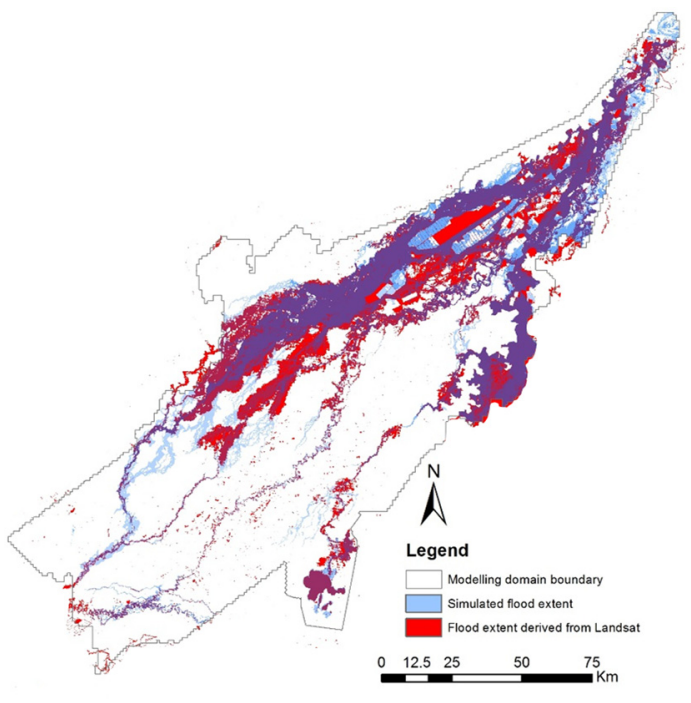

Date: $21 / 01 / 2011$

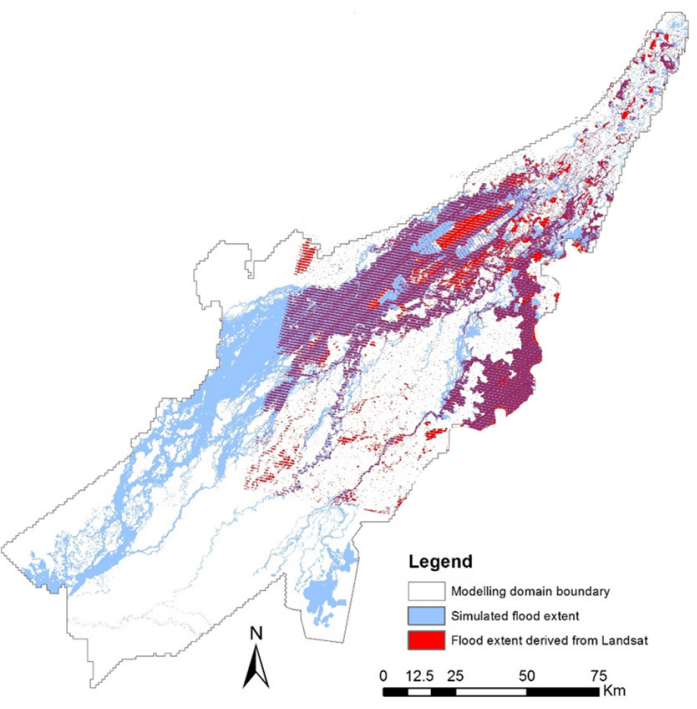

Date: $17 / 02 / 2012$

Figure 4. Comparison between the simulated flood extents and flood maps from Landsat imagery for two dates (21/01/2011 and 17/02/2012) covering two simulated flood events. The areas with overlap of simulated and Landsat flood maps appear in purple color. 


\section{FLOOD DATABASE}

Due to very high computational time and storage requirement, it was not possible to undertake continuous simulation using the 2D hydrodynamic model for multiple years covering flows of all ranges at high spatiotemporal resolutions. Therefore, to model inundation extents representing different ranges of overbank flow events, three synthetic flood hydrographs were generated based on the historical flow data over 100 years. Using the magnitudes of peak flows of all historical flood events from 1911-2014, three ranges were identified for generating synthetic hydrographs of flood events, which were $20-30 \%, 45-55 \%$ and $95-100 \%$ of flood peaks. For each of the selected ranges, a 41-day synthetic hydrograph was generated at a reference gauge by taking mean of all daily flow time series within the selected peak flood range covering 20 prior and 20 days after each peak. For all other gauges within a modelling domain (which were used as inflow nodes), synthetic hydrograph for a particular range was prepared by taking the mean of the daily flow data for the same time periods as the reference gauge for the particular range. Similarly, rainfall, potential evapotranspiration (PET) and runoff for ungauged areas within the modelling domain was prepared by taking the mean of the daily runoff for the same time period as the reference gauge for the particular range. This was done to obtain the representative rainfall, PET and runoff with due consideration of spatial and temporal variations. Figure 5 presents the synthetic hydrographs for the reference gauges for the four modelling zones.

The calibrated MIKE21 HD model was used to simulate flood inundation using the three synthetic hydrographs as the boundary conditions at $90-\mathrm{m}$ resolution. The results were resampled to 5-m using the simplified hydraulic model and then, the water balance model was used to under water balance analysis under three antecedent soil moisture conditions: dry soil, medium wet soil and fully saturated soil using 5-m resolution daily inundation maps. Figure 6 shows the examples of the simulated inundation maps on day 10 of the 41 -day period for $45-55 \%$ event under three different antecedent soil moisture conditions. As can be seen from the figure, the extent of the inundation for the same day under dry soil moisture condition is relatively smaller compared to medium and wet soil moisture conditions. The difference in the inundation extent for dry and wet condition can be clearly seen from Figure $6 \mathrm{~d}$.

Water balance summary for each of the simulated flood event was produced for the modelling domain, which included average daily rainfall and potential evaporation, inflow discharge at reference gauge and infiltration from flooded area and net flooded area under the three different antecedent conditions. Figure 7 shows the variation in the net flooded area for different days of the simulation of $95-100 \%$ range flood events under the three antecedent soil moisture conditions. With the increase in flow, the inundation extent increases and the differences in the flooded areas under the three antecedent conditions become larger. But these differences reduce as the flood recedes due to filling up of the

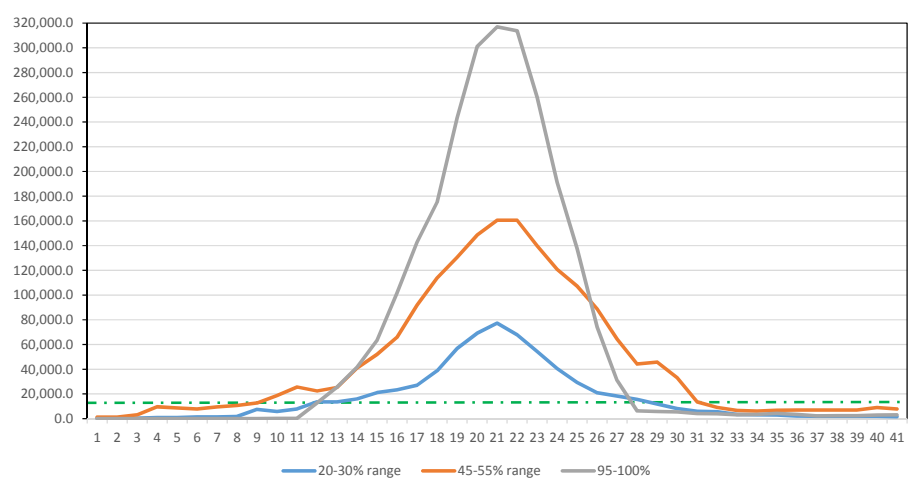

Figure 5. Synthetic hydrographs at 422201 (St George) for three different ranges of floods from 1911-2014. Dotted green shows the overbank flow threshold ( 15,000 ML/day).

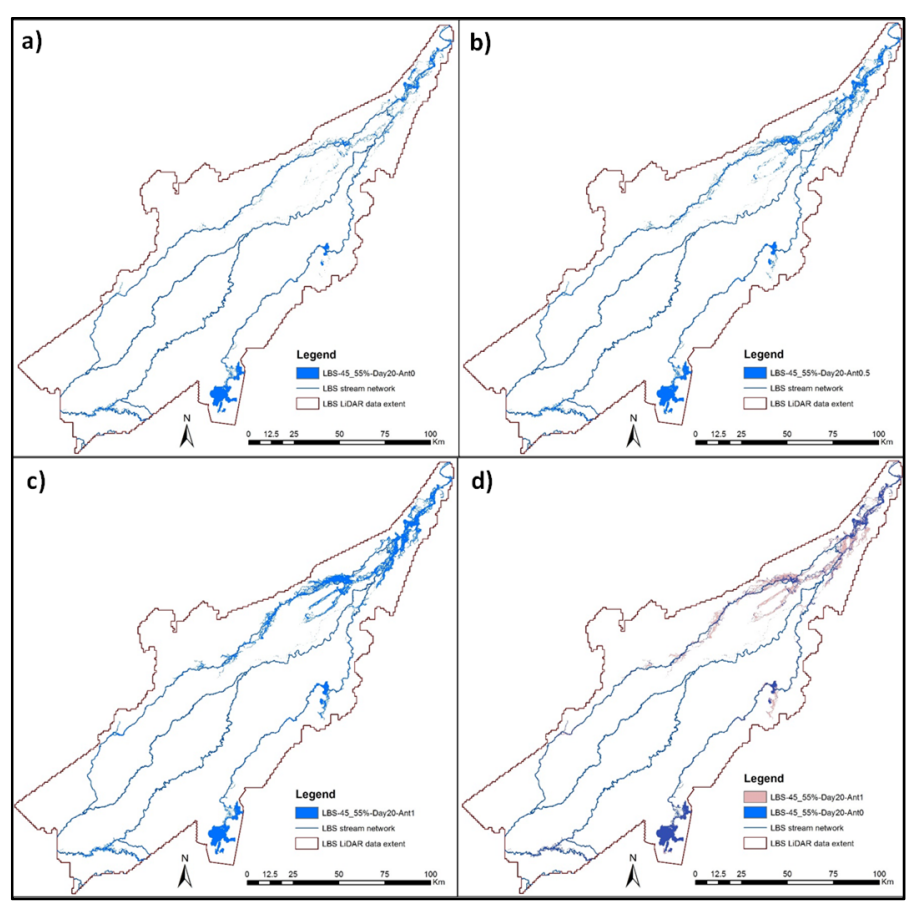

Figure 6. 5-m resolution simulated inundation extents on Day 20 for $45-55 \%$ range flood event under different soil moisture conditions: a) dry, b) medium, c) wet, d) dry and wet. 
Dutta et al., Building a Comprehensive Spatio-Temporal Database of Floodplain Inundation ......

floodplain soil storages. The difference in the flooded area is higher between the dry and medium soil moisture conditions compared to the medium and wet soil moisture conditions.

\section{CONCLUSIONS}

In this study, an innovative large-scale floodplain modelling approach was developed by integrating a suite of models (landscape model, hydrodynamic model and water balance model) and GIS for producing inundation maps at very high temporal and spatial resolutions under different antecedent conditions.

In the inundation modelling, a combination of hydrodynamic, simplified hydraulic and water balance modelling was used to undertake inundation simulation for a series of synthetic flood events under three different antecedent conditions. Prior to undertaking scenario modelling using synthetic flood events, the hydrodynamic

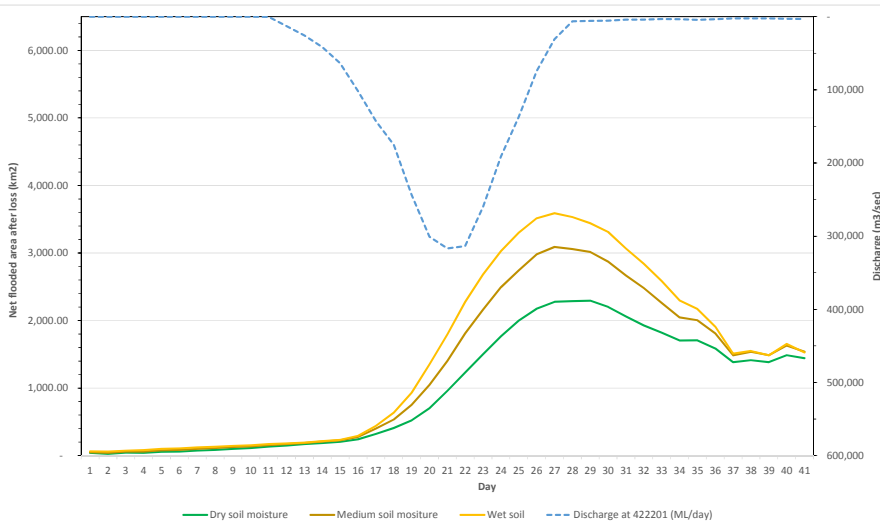

Figure 7. Simulated net flooded areas for different days of simulation for the $95-100 \%$ range flood event under three antecedent soil moisture conditions: dry, medium and wet.

model was calibrated and validated using the observed water level data at different gauges and flood maps derived from the Landsat imagery. The final results of the model calibration and validation demonstrated the satisfactory performance of the model in terms of the water level simulations in various locations The simulated inundation extents showed reasonably good matching with the flood extents derived from Landsat imagery for different dates during the selected flood events in all the modelling zones. The results of scenario modelling demonstrated the ability of the model to simulate flood inundation under different antecedent conditions. The effects of antecedent soil moisture conditions on inundation characteristics were found to be highly significant.

\section{ACKNOWLEDGMENTS}

The authors gratefully acknowledge the financial support provided by the MDBA and CSIRO.

\section{REFERENCES}

Dutta D, Teng J, Vaze J, Lerat J, Hughes J, Marvanek S. (2013). Storage-based approaches to build floodplain inundation modelling capability in river system models for water resources planning and accounting. Journal of Hydrology, 504:12-48.

Dutta D, Nakayama K (2009). Effects of Spatial Grid Resolution on River Flow and Surface Inundation Simulation by Physically Based Distributed Modeling Approach, Hydrological Processes, 23:534-545.

Environment Australia (2001). A Directory of Important Wetlands in Australia, Third Edition. Canberra.

Horton, Robert E. (1933). The role of infiltration in the hydrologic cycle. Trans. Am. Geophys. Union. 14th Ann. Mtg: 446-460.

McCosker, RO (1996). An environmental scan of the Condamine-Balonne River system and associated floodplain, LANDMAX Natural Resource Management Services, Armidale, New South Wales.

MDBA (2012a). Basin Plan, The Murray-Darling Basin Authority, http://www.mdba.gov.au/sites/default/files/ Basin-Plan/Basin-Plan-Nov2012.pdf

MDBA (2012b). Assessment of environmental water requirements for the proposed Basin Plan: Lower Balonne Floodplain, MDBA Publication No: 24/12, Murray-Darling Basin Authority for and on behalf of the Commonwealth of Australia, 2012.

Powell SJ, Letcher RA, Croke BFW (2008). Modelling floodplain inundation for environmental flows: Gwydir wetlands, Australia, Ecological Modelling, 211:350-362.

Teng J, J Vaze J, Dutta D, Marvanek S (2015). Rapid inundation modelling in large floodplains using LiDAR DEM, Water Resources Management, 29(8): 2619-2636.

Thoms M, Quinn G, Butcher R, Phillips B, Wilson G, Brock M, Gawne B (2002). Scoping study for the Narran Lakes and Lower Balonne floodplain management study (R2011), Cooperative Research Centre for Freshwater Ecology, Canberra.

Vaze J, Chiew FHS (2003). Comparative evaluation of urban stormwater quality models. Water Resources Research, Vol. 39, NO. 10, 1280

Viney N, Vaze J, Crosbie R, Wang B, Dawes W, Frost A (2014). AWRA-L v4.5: Technical description of model algorithms and inputs. 76 pages, CSIRO, Australia. 